\title{
Family expectation, social adjustment and gender differences in a sample of schizophrenic patients
}

\section{Expectativa familiar, ajustamento social e diferenças entre os gêneros numa amostra de pacientes esquizofrênicos}

\author{
Itiro Shirakawa, Jair J. Mari, Ana C. Chaves and Marcelo Hisatsugo \\ Departamento de Psiquiatria e Psicologia Médica da Universidade Federal de São Paulo. São Paulo, \\ SP-Brasil
}

\begin{abstract}
A case series to study factors related to family expectation regarding schizophrenic patients was conducted in an out-patient setting in the city of S. Paulo, Brazil. Patients diagnosed as presenting schizophrenia by the ICD 9th Edition and having had the disease for more than four years were included in the study. Family Expectation was measured by the difference between the Katz Adjustment Scale (R2 and R3) scores based on the relative's expectation and the socially expected activities of the patient (Discrepancy Score), and social adjustment was given by the DSM-III-R Global Assessment Scale (GAS). Outcome assessments were made independently, and 44 patients comprised the sample (25 males and 19 females). The Discrepancy mean score was twice as high for males as for females $(p<0.02)$, and there was an inverse relationship between the discrepancy score and social adjustment $(\mathrm{r}=-0.46, \mathrm{p}<$ 0.001). Moreover, sex and social adjustment exerted independent effects on the discrepancy score when age, age at onset and number of psychiatric admissions were controlled by means of a multiple regression technique. There was an interaction between sex and social adjustment, the inverse relationship between social adjustment and discrepancy score being more pronounced for males. These findings are discussed in the light of the potential association between the family environment, gender and social adjustment of schizophrenic patients, and the need for further research, i.e. ethnographic accounts of interactions between patient and relatives sharing households particularly in less developed countries.
\end{abstract}

Schizophrenia. Social adjustment. Family, psychology.

\section{Resumo}

Foi realizado estudo de corte transversal para estudar fatores associados às expectativas familiares com familiares ambulatoriais esquizofrênicos pela Classificação Internacional de Doenças, 9a edição e que tivessem mais de 4 anos de duração da doença foram incluídos no estudo. A expectativa familiar

Correspondence to: Itiro Shirakawa - Departamento de Psiquiatria e Psicologia Médica da Universidade Federal de São Paulo. Rua Botucatu, 740 -

$3^{\circ}$ andar - 04023-900 São Paulo, SP - Brasil. Fax: (011) 549.2127

Edição subvencionada pela FAPESP. Processo 95/22090-6.

Received on: 9.25.1995. Approved on 1.12.1996. 
foi medida pela diferença dos escores da Escala de Ajustamento Katz (R2 e R3), que são baseados nas expectativas dos familiares e no nivel atual de desempenho das atividades socialmente esperadas (Escore de Discrepância). $O$ ajustamento social foi medido através da Escala de Avaliação Global (GAS) do DSM-III-R. As avaliações dos desfechos clínicos foram realizadas independentemente, e a amostra foi constituida por 44 pacientes (25 homens e 19 mulheres). A média do Escore de Discrepância foi duas vezes maior para os homens do que para as mulheres $(p<0,02)$, e houve uma associação inversa entre o escore de discrepância, quando idade atual e idade de início da doença, e número de admissões psiquiátricas foram controladas através de uma técnica de análise de regressão múltipla. Houve interação entre sexo e ajustamento social, uma relação inversa entre ajustamento social e escore de discrepância mais pronunciada nos homens. Estes achados são discutidos diante das associações potenciais entre atmosfera familiar, gênero e ajustamento social dos pacientes esquizofrênicos e a necessidade de haver mais pesquisas nesta área, p.ex., descrições etnográficas das interações entre pacientes e familiares no ambiente doméstico, particularmente, nos paéses menos desenvolvidos.

Esquizofrenia. Ajustamento social. Família, psicologia.

\section{INTRODUCTION}

Schizophrenia is a disruptive illness both for the individual and for the family. The disease is not evident when the child is borne and for a considerable period of life social function and performance seem normal. The acceptance of the illness is usually very difficult for the relatives, and it is especially hard if the person with schizophrenia had been promising prior to becoming ill.

Brown et al. ${ }^{4}$ conducted a longitudinal prospective study in 101 inpatients with schizophrenia or related disorders by PSE to test if a high degree of Expressed Emotion (EE) would be a predictive factor of relapse. The feelings expressed by relatives were measured by means of a semi-structured interview which attributed ratings based on vocal aspects of speech, such as tone and pitch, and on the content of the relative's report. The interview had the following components: a) critical comments, which were judged by the tone of the voice and/or a clear statement of resentment, disapproval or dislike; b) hostility, indicating rejection and generalized critical comments; c) emotional over-involvement, for rating unusually marked concerns about the patient and/or anxiety demonstrated with regard to unimportant problems; and d) warmth, the only positive rating incorporated comments of support and spontaneous demonstration of sympathy and concern. The patients were followed up for 9 months and the proportion of relapse was 58\% among these patients, who had high EE relatives and 16\% among those, who had low EE relatives. Relapse was much higher for males $(50 \%)$ than females $(21 \%)$. These findings were later replicated by Vaughn \& Leff $^{25}$ in a prospective cohort of 37 schizophrenic patients. The relapse rate was $48 \%$ among high EE relatives and $6 \%$ among low EE. Schizophrenic males had a relapse rate higher than females, unmarried men being at highest risk of relapse.

Seeman ${ }^{19}$ pointed out that current gender differences allow families to harbor educational and achievement expectations for their schizophrenic sons long after they have resigned themselves to a more modest future for their schizophrenic daughters. In developing countries, the expectations of the family as regards social role performance are probably higher for males than females, where males still constitute the predominant work-force and income providers.

After the publication of the British researchers, many investigations were conducted using the Camberwell Family Interview (CFI): in California ${ }^{26}$, Denmark and North India ${ }^{29,30}$, Italy ${ }^{5}$ and Greece ${ }^{17}$. These studies showed cross-cultural variations in the schizophrenic's relative's expressed emotions and based on these results some authors concluded that EE could be a major factor explaining the better outcome of schizophrenia in developing countries ${ }^{14}$.

Martins et al. ${ }^{16}$ conducted a cross sectional study in Porto Alegre (in Southern Brazil) to test the hypothesis that the majority of relatives will show a low EE pattern and among high EE families it is predicted that a majority will be so because of high levels of emotional over-involvement. Twenty-nine relatives of 24 schizophrenic inpatients by ICD-9 were inter- 
viewed using the Portuguese/Brazilian version of CFI. Most of the patients were male, unmarried and lived with their parents (the actual numbers of males/females were not mentioned in the text). Of the 29 relatives 59\% were assigned to high EE categories, a result contrary to that foreseen by the investigators.

Due to the scarcity of studies involving relatives of schizophrenic patients in less developed countries, of the present study the aim is the investigation of gender differences in the relationship between social performance and family expectations in an out-patient sample of schizophrenic patients in Brazil.

\section{METHOD}

A case-series survey for the study of factors related to family expectation of schizophrenic patients was conducted in a private out-patient setting in the city of S. Paulo, Brazil. All the patients of the clinic under the care of a single psychiatrist (I.S.), diagnosed as presenting schizophrenia by the ICD 9th Edition, clinically stabilized, and having had the disease for more than four years were included in the study.

Two sections of the Katz Adjustment Scales ${ }^{11}$ were used to assess: a) the level of performance of socially expected activities of the patient at his/her best (R2); and b) the level of the families' expectations of the patients (R3). In addition, the Discrepancy Score (DS) was measured by the difference between the total scores of the two sections described (R3-R2), i.e. the difference between the relative's expectation and the actual performance of the patient. Social adjustment was given by the DSM-IIIR Global Assessment Scale (GAS) ${ }^{1}$. The lower the GAS the lower the social performance. Outcome assessments were made independently. The clinician (I.S.) attributed the GAS scores and a trained medical undergraduate applied the Katz interviews to a key relative. The clinician was blind to the Katz scores and the interviewer was blind to the aims of the study.

The data analysis was carried out by means of the SPSS package for micro computers, version 3.1. The $\mathrm{x}^{2}$ test was applied for differences between dichotomous variables and the Student t-test for mean differences between two groups. The Spearman correlation was applied to evaluate the relationship between continuous variables. Multiple regression analysis was carried out with Discrepancy Score as the dependent variable and the explanatory variables were selected as follows: social adjustment scale, sex, age, age at onset, and number of previous psychiatric admissions. They were all treated as continuous variables but sex was treated as an indicator variable, being 0 for males and 1 for females. As the sample size was very small and duration of illness correlated strongly with age at last birthday it was decided to exclude duration of the illness from the multiple regression analysis. The method used in the package was the "ENTER" command aiming to force all the variables in the equation. All the violations of assumptions were checked according to Kleinbaum et al. ${ }^{13}$ An analysis of covariance was carried out to investigate whether the Discrepancy Scores differed significantly after taking into account the possible confounding effects of differing age and social adjustment distributions in the two groups (male and female).

\section{RESULTS}

Forty-four patients comprised the sample ( 25 males and 19 females). Age at last birthday ranged from 23 to 46 years old, and the mean was 33 years (s.d. = 6.70). There was no difference between the sexes in age distribution. Regarding marital status, 35 (79.5\%) had never married, $5(11.4 \%)$ were married, $3(6.8 \%)$ separated, and $1(2.3 \%)$ widowed. Women had a higher proportion of marriages but differences were not statistically significant. Most of the sample had attained high school level $(\mathrm{n}=30)$, and $6(13.6 \%)$ patients managed to earn a regular income by doing some kind of work. Table 1 shows the first-episode diagnostic distribution of the sample by sex and there were no significant differences between the sexes.

The mean scores of social adjustment (GAS), the total scores on the Katz scales (R2 and R3), the discrepancy score (DS), age, age at onset, duration of the illness and number of admissions between the two sexes are displayed in Table 2. As can be seen in Table 2 the Discrepancy Score was twice as high for males as for females, and this difference was statistically significant. There were no significant differences between males and females regarding social adjustment, family expectations, age, age at onset, duration of the illness and number of psychiatric admissions. Females presented

Table 1 - Diagnostic distribution (ICD - 9) by sex.

\begin{tabular}{lrrrrrr}
\hline Diagnostic & \multicolumn{3}{c}{ Male } & \multicolumn{2}{c}{ Female } & \multicolumn{2}{c}{ Total } \\
\cline { 2 - 7 } & $\mathrm{n}$ & \multicolumn{1}{c}{$\%$} & $\mathrm{n}$ & $\mathrm{n}$ & \multicolumn{1}{c}{$\%$} \\
\hline Hebephrenic & 2 & 8.0 & 5 & 26.3 & 7 & 15.9 \\
Paranoid & 22 & 88.0 & 13 & 68.4 & 35 & 79.6 \\
Latent & 0 & - & 1 & 5.3 & 1 & 2.3 \\
Residual & 1 & 4.0 & 0 & - & 1 & 2.3 \\
\hline Total & 25 & 100.0 & 19 & 100.0 & 44 & 100.0 \\
\hline
\end{tabular}


Table 2 - The mean distributions for discrepancy score, global adjustment scale, socially expected activities, family expectations, age, age at onset, duration of the illness, and number of admissions by sex.

\begin{tabular}{lcccccc}
\hline Distribution & \multicolumn{2}{c}{ Male } & \multicolumn{2}{c}{ Female } & \multicolumn{2}{c}{ Total } \\
\cline { 2 - 7 } & Mean & s.e. & Mean & s.e. & Mean & s.e. \\
\hline Discrepancy score & 10.08 & 1.40 & $4.84^{*}$ & 1.31 & 7.82 & 1.04 \\
Global adjustment score & 54.20 & 2.60 & 55.95 & 2.96 & 54.96 & 1.93 \\
Socially expected activities & 26.56 & 1.14 & $30.84^{*}$ & 1.06 & 28.41 & 0.85 \\
Family expectations (R3) & 36.64 & 1.27 & 35.68 & 1.17 & 36.23 & 0.88 \\
Age at last birthday & 32.04 & 1.46 & 34.16 & 1.33 & 32.96 & 0.88 \\
Age at onset & 21.48 & 1.05 & 23.21 & 1.34 & 22.23 & 0.83 \\
Duration of the illness & 10.56 & 1.20 & 10.95 & 1.09 & 10.73 & 0.82 \\
Number of admissions & 2.64 & 0.67 & 2.32 & 0.66 & 2.50 & 0.47 \\
\hline
\end{tabular}

$* p<0.02$.

s.e. - standard error.

a statistically significant better performance than males as regards socially expected activities.

The correlation matrix of the Discrepancy Score, the Global Adjustment Scale, sex, age, age at onset, duration of the illness and number of previous psychiatric admissions are displayed in Table 3 . There is an inverse relationship between social adjustment and discrepancy score: the higher the expectation the lower the social adjustment. The relation between sex and the discrepancy score was negative showing that males correlated better with DS than females. The two highest correlations were between age and age at onset $(\mathrm{r}=0.619)$, and between age and duration of the illness $(\mathrm{r}=0.604)$. Moreover, the total score of the level of families' expectations was correlated with the total social adjustment score for males and females. An inverse relationship was found for males $(r=-0.22)$ and a positive relationship for females $(\mathrm{r}=+0.25)$, but these findings were not statistically significant. There was a positive association between family ratings and social performance on the Katz scales for males and females ( $\mathrm{r}$ $=+0.33,+0.32$, respectively), though it was not statistically significant.

\section{The Multiple Regression Analysis}

The frequency distribution of the Discrepancy Scores (DS) against a normal curve can be seen in
Figure. The minimum DS value was -9 and the maximum value 24.0, the range being 33.0. The DS mean score was found to be 7.82 (s.e. 1.04). The median was 7.5 and the mode 4.0. The distribution of the Discrepancy Scores has two peaks (one at the midpoint -0.26 and the other at the mid point 9.44 ), resembling the shape of a bimodal curve. The skewness of the curve was positive, but not very high $(0.29$, s.e. 0.36$)$.

The regression model yielded the following results: R Square was 0.39 and the adjusted R Square 0.31 ( $\mathrm{F}=4.85,5,38$ d.f., $\mathrm{p}<0.002)$ and the parameter estimates are shown in Table 4. Sex and social adjustment exerted statistically significant independent effects on the Discrepancy Score.

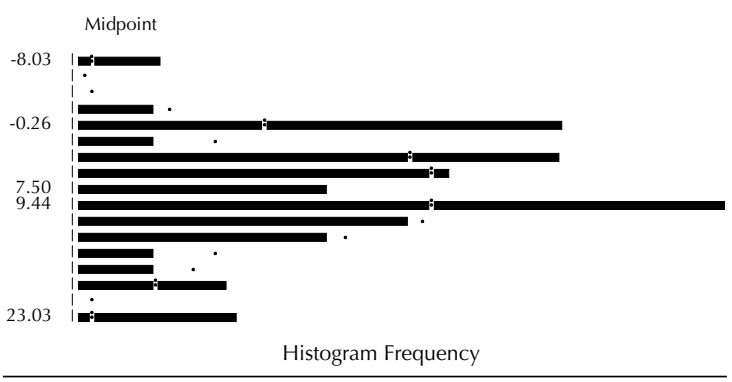

Figure - The frequency distribution of the Katz Discrepancy Scores with a normal curve.

Table 3 - The correlation matrix of the discrepancy score, the global adjustment scale (GAS), age, age at onset, duration of the illness, sex and number of psychiatric admissions.

\begin{tabular}{|c|c|c|c|c|c|c|}
\hline Correlaction & GAS & $\begin{array}{c}\text { Duration of } \\
\text { illness }\end{array}$ & $\begin{array}{l}\text { Age at } \\
\text { onset }\end{array}$ & $\begin{array}{l}\text { Age at last } \\
\text { birthday }\end{array}$ & $\operatorname{sex}$ & $\begin{array}{l}\text { Number of } \\
\text { admissions }\end{array}$ \\
\hline Discrepancy score & $-4.5^{* *}$ & 0.14 & -0.33 & -0.16 & $-0.38^{*}$ & -0.07 \\
\hline GAS & & -0.17 & 0.31 & 0.11 & 0.07 & $-0.41^{*}$ \\
\hline Duration of illness & & & -0.25 & $0.60 * *$ & 0.04 & 0.09 \\
\hline Age at onset & & & & $0.62 * *$ & 0.16 & 0.18 \\
\hline Age at last birthday & & & & & 0.16 & 0.13 \\
\hline Sex & & & & & & -0.05 \\
\hline
\end{tabular}

1-tailed significance: ${ }^{*} \mathrm{p}<.01:{ }^{* *} \mathrm{p}<.001$.

+ Sex was 0 for males and 1 for females

GAS - Global Adjustment Scale. 
Tabel 4 - The parameter estimates for the joint effects of social adjustment, age, age at onset, number of psychiatric admissions, and sex, on the discrepancy score.

\begin{tabular}{lccrc}
\hline Variable & $\mathrm{b}$ & $\mathrm{s} . \mathrm{e}$ & $\mathrm{t}$ & $\mathrm{p}$ \\
\hline GAS & -0.264 & 0.082 & -3.204 & 0.0027 \\
Sex & -4.809 & 1.786 & -2.693 & 0.0105 \\
Age & 0.086 & 0.169 & 0.511 & 0.6121 \\
Admissions & -0.495 & 0.327 & -1.515 & 0.1381 \\
Age onset & -0.180 & 0.217 & 0.830 & 0.4117 \\
(Constant) & 26.774 & 5.702 & 4.696 & 0.0000 \\
\hline
\end{tabular}

GAS - Global Adjustment Scale

s.e. - standard error.

The introduction of sex has increased the proportion of the variation in the dependent variable from 0.20 to 0.31 , an statistically significant increment $(\mathrm{F}=7.25,1,38$ d.f., $\mathrm{p}<0.02)$. Moreover, the tolerance, i.e. a measure of the independence of each explanatory variable of the other regressors, showed a good degree of independence as follows: sex, 0.96; age, 0.60; age at onset, 0.54; social adjustment, 0.69; and number of admissions, 0.74. Further details of this concept can be found elsewhere ${ }^{8}$.

\section{Checking for Violation of Assumptions}

Kleinbaum et al. ${ }^{13}$ recommended checking for the violation of assumptions (linearity, equality of variance and normality of distribution of residuals) in the use of multiple regression analysis. A convenient method of assessing linearity is to plot residuals against the predicted values of the dependent variable. Systematic patterns between the predicted values and the residual suggest possible violations of the linearity assumptions. The standardized scatterplot between the predicted values of Discrepancy Score and Residuals did not show any systematic relationship between these two variables. Regarding equality of variance, if the spread of the residuals increases or decreases with values of the independent variables the assumption of constant variance of $Y$ for all values of $X$ can be questioned. The residuals were thus plotted against age, age at onset, social adjustment and number of psychiatric admissions. None of the independent variables showed a systematic relationship with residuals, leading us to conclude that the assumption of equality of variance has not been violated. The distribution of residuals should be normal. The histogram distribution of the standardized residuals was compared with a normal curve. None of the residuals showed a value greater than 3.0 standard deviations.

The Discrepancy Scores are statistically independent of each other, and the model found did not violate assumptions needed to draw inferences about the population from which the sample was taken. Therefore it can be concluded that sex and social adjustment exerted statistically significant independent effects on the Discrepancy Score (though the proportion of the explained variation was not terribly high). The next step will be to check for covariance of sex and social adjustment and sex and age.

\section{Analysis of Covariance}

The question here is to investigate whether the Discrepancy Scores differ significantly after taking into account the possible confounding effects due to differing age and social adjustment distributions in the two groups (male and female). There was a clustering at the beginning of the tail and two peaks in the centre of the curve. Some deviation from normality is to be expected because of sampling variation but the normality assumption might have been violated due to minor confounding effects of differing age and social adjustment distributions in the two groups (male and female).

The first step was to model sex and social adjustment alone. R Square was 0.33 and the Adjusted R Square $0.30(\mathrm{~F}=10.04,2,41$ d.f., $\mathrm{p}<0.001)$. The two independent effects of sex and social adjustment were statistically significant as predicted by the previous model. Then the interaction of sex and social

Table 5 - The parameter estimates for joint effects of sex and social adjustment on the discrepancy score.

\begin{tabular}{|c|c|c|c|c|}
\hline Variable & $\mathrm{b}$ & s.e. & $\mathrm{t}$ & $p$ \\
\hline GAS & -0.264 & 0.082 & -3.204 & 0.0027 \\
\hline Sex & -4.809 & 1.786 & -2.693 & 0.0105 \\
\hline Interaction & 0.086 & 0.169 & 0.511 & 0.6121 \\
\hline (Constant) & 26.774 & 5.702 & 4.696 & 0.0000 \\
\hline
\end{tabular}


adjustment was forced into the model from which an R Square of 0.41 and an adjusted R Square of 0.37 ( $\mathrm{F}=9.31,3,40$ d.f., $\mathrm{p}<0.001)$ resulted. As can be seen in Table 5 the interaction between sex and social adjustment was statistically significant. The two equations are summarised as follows:

For males: DS $=29.94-0.36 \mathrm{GAS}$

For females: DS $=7.78-0.04 \mathrm{GAS}$

The two slopes are negative, i.e. there is an inverse relationship between social adjustment and Discrepancy Scores for both groups but this effect was more pronounced for males (F [SEX.GAS/ SEX,GAS] $=5.59,1,40$ d.f., $p<0.025$ ). Age adjustment of discrepancy scores did not result in significant by different estimates for the two groups compared (male and female).

\section{DISCUSSION}

The socially expected activities (R2) was higher for women than for men, but there were no gender differences regarding family expectations (R3). As the Discrepancy (R3-R2) mean score was twice as high for males as for females (two tailed t-test $=2.66$, 42 d.f., $\mathrm{p}<0.02$ ), this difference should be attributed to R2, i.e. the socially expected activities. There was also an inverse relationship between the discrepancy score and social adjustment $(\mathrm{r}=-0.46, \mathrm{p}<0.001)$. Moreover, sex and social adjustment exerted independent effects on the discrepancy score when age, age at onset and number of psychiatric admissions were controlled by means of a multiple regression technique. The assumptions of linearity, equality of variance and normality, needed to apply the multiple regression technique, have all been checked, and no major violations were found such as might affect possible inferences from the study population. There was an interaction between sex and social adjustment, and the inverse relationship between social adjustment and discrepancy score was more pronounced for males.

The findings of this study have to be viewed with caution. The sample size is small, data were gathered in just one out-patient clinic with all the constraints of a cross sectional design. It is not possible to know, for example, the direction of such a relationship. The other limitation is the operationalized way "family expectation" was applied, i.e. by defining it as the difference between two scales there is an increased probability of random error. We were aware of this risk but it was decided to express family expectations taking into account the actual per- formance of the patient. As has been shown here family expectations were similar for both sexes when compared in isolation, but when the lower social performance of males is considered, it must be remembered that they would be under more pressure than females to improve social performance. There are many reasons to believe that these findings may indeed reflect cultural and gender differences of families' expectations as to patients' social performance: the acknowledgment that deviant behaviour is less tolerated among males ${ }^{23}$; the interviewer was blind to the aims of the study; the Katz ratings are more reliable for stabilized patients ${ }^{18}$; and these results are consistent with clinical and sociological empirical observations.

Barrowclough \& Tarrier $^{3}$ have compared baseline ratings of $E E$ with the levels of social functioning of patients from high EE and low EE households in their efficacy trial of a behavioral psychosocial intervention $^{20,21}$. They also found that ratings of EE were significantly associated with lower social functioning particularly with hostility, but they did not explore the differences between the sexes in their study. Indeed, males and females are expected to be equally distributed in high EE homes ${ }^{24}$ but more males return to conflicting environments after hospital discharge $e^{4,25}$.

Family concerns are different for men and women. Seeman ${ }^{19}$ made peculiar observations when collaborating with a support and educational program for relatives of schizophrenic patients ${ }^{22}$. In summary, families of males are concerned with impulsive sexuality, aggression and impulsivity while families of females are more concerned about their daughters being sexually abused or becoming pregnant.

The fact that females presented a better performance than males as regards socially expected activities has been confirmed by many investigators. It is very likely that men present their first symptoms of the disease earlier than women, and tend to be admitted to hospital 4 to 5 years earlier than females ${ }^{2}$. Females present a better course of the illness ${ }^{27}$, and experience significantly fewer rehospitalizations and shorter hospital stays than males 9 . In the IPSS fiveyear follow-up, males presented a poorer outcome than females regarding the time they spent under a psychotic episode, in the pattern of the course of the illness and social adjustment ${ }^{14}$.

The term social adjustment is subjected to a normative bias as pointed out by Corin ${ }^{7}$. According to Weissman ${ }^{28}$, social adjustment is the interaction between the individual and social environment. Social roles are specific behavior patterns normally recog- 
nized as appropriate and always related to the sociocultural background of the population under study. Social adjustment is the result of the interaction between the individual and others, his/her social role performance which may be modified by personality, culture and family expectations.

Klein et al. ${ }^{12}$ investigated the effect of family and community variables on social adjustment and rehospitalizations with a sample of consecutive admissions in Turkey and the USA. Katz scales were used to assess outcome and patients who were readmitted to hospital had performed more socially expected activities than those who remained in the community. Moreover, they noticed that the greater the family ratings on expectation the higher the patients' performance of socially activities. They concluded that families showing more tolerance contributed to the prevention of rehospitalization. In summary, the higher the family's expectations the higher the socially expected activities but at the cost of increasing risk of hospital admissions. The association between social performance and family expectations as measured by the Katz scale was also positive in this study but there was no statistical significance in the correlations for men and women. This study was not concerned with relapses but such a relation is very likely to be closer for males than for females.

\section{REFERENCES}

1. AMERICAN PSYCHIATRY ASSOCIATION. Diagnostic and statistical manual of mental disorders. 3rd. ed. revised (DSM-III-R). Washington, D.C., American Psychiatric Press, 1987.

2. ANGERMEYER, M. C. \& KUHN, L. Gender differences in age of onset of schizophrenia. Eur. Arch. Psychiatr. Neurol. Sci., 237: 351-64,1988.

3. BARROWCLOUGH, C. \& TARRIER, N. Social functioning in schizophrenic patients: the effects of expressed emotion and family intervention. Soc. Psychiatry Psychiatr. Epidemiol., 25: 125-9, 1990.

4. BROWN, G. W., BIRLEY, J. L. T.; WING, J. K.. Influence of family life on the course of schizophrenic disorders: a replication. Br. J. Psychiatry, 121: 241-58, 1972.

5. CAZZULLO, C. L.; BRESSI, C.; BERTRANDO, P.; CLERICI, M.; MAFFEI, C. Schizophrenie et expression emotionnelle familiale: etude d'une population italienne. Encephale., 15: 1-6, 1989.

6. CHAVES, A.C.; SEEMAN, M.V.; MARI, J.J.; MALUF. A Schizophrenia: impact of positive symptoms on gender social role. Schizophr. Res., 11:41-5, 1993.
Another important fact is related to the earlier onset of the disease among males, a phenomenon which has also been observed in Brazil ${ }^{6,15}$. Women tend to get married earlier than men. Therefore by the time they are likely to present the first symptoms of the disease, women have built-up other intimate relationships. As the symptoms break out earlier for males, the onset occurs while they are still living with their families. Thus, it is expected that the family will blame themselves more intensively in the case of a male offspring. In the case of women, there are also other factors such as a broken love affair or marriage which can operate as a channel for the relief of family guilt ${ }^{19}$.

The role of the housewife is characterized by its unstructured and invisible features. As pointed out by Gove \& Tudor ${ }^{10}$ "it is possible for the housewife to put things off, to let things slide, in sum, to perform poorly".

By considering family expectation as the difference between social performance and family ratings, on the Katz scale, an inverse relationship was found here between social adjustment and family expectations its strength being more pronounced among males. While these findings might indeed be representing part of the "family expectation" phenomena it is advisable to view them as hypothesis generating for further research with relatives of schizophrenic patients.

7. CORIN, E. Facts and meaning in psychiatry. An anthropological approach to the lifeworld of schizophrenics. Cult. Med. Psychiatry, 147:602-7, 1990.

8. DARLINGTON, R. B. Regression and linear models. New York, McGraw Hill, 1990.

9. GOLDSTEIN, J. M. Gender differences in the course of schizophrenia. Am. J. Psychiatry, 145: 684-9, 1988.

10. GOVE, W. R. \& TUDOR, J. F. Adult sex roles and mental illness. Am. J. Sociol., 78: 813-35, 1973.

11. KATZ, M. M. \& LYERLY, S.B. Methods for measuring adjustment and social behaviour in the community: a rationale, description, discriminative validity and scale development. Psychol. Rep., 13: 505-35, 1963.

12. KLEIN, H. E.; PERSON, T. M.; CETINGOK, M.; TURAN, M. I. Family and community variables in adjustment of Turkish and Missouri schizophrenics. Compr. Psychiatry, 19: 233-40, 1978.

13. KLEINBAUM, D. G; LAWRENCE, L. K.; KEITH, E. M. Applied regression analysis and other multivariable methods. Boston, PWS-KENT Publishing Company, 1988. 
14. LEFF, J.; SARTORIUS, N.; JABLENSKY, A.; KORTEN, A.; ERNBERG, G. The international pilot study on schizophrenia: Five-year follow-up findings. Psychol. Med., 22: 131-45, 1992.

15. MARI, J. J. A epidemiologia da esquizofrenia. J. Bras. Psiquiatr, 38:180-4, 1989.

16. MARTINS, C.; LEMOS, A. I.; BEBBINGTON, P. E. A Portuguese/Brazilian study of expressed emotion. Soc. Psychiatry Psychiatr. Epidemiol., 27: 22-7, 1992.

17. MAVREAS, V. G.; TOMARAS, V.; KARYDI, V.; ECONOMOU, M.; STEFANIS, C. N. Expressed emotion in families of chronic schizophrenics and its association with clinical measures. Soc. Psychiatry Psychiatr. Epidemiol., 27: 4-9, 1992.

18. PARKER, G. \& JOHNSTON, P. Reliability of parental reports using the Katz adjustment scales: before and after hospital admission for schizophrenia. Psychol. Rep., 65: 251-8, 1989.

19. SEEMAN, M. V. Schizophrenic men and women require different treatment programs. J. Psychiatr. Treat. Evaluat., 5: 143-8, 1983.

20. TARRIER, N.; BARROWCLOUGH, C.; VAUGHN, C.; BAMRAH, J. S.; PORCEDDU, K.; WATTS, S.; FREEMAN, $\mathrm{H}$. The community management of schizophrenia: a controlled trial of a behavioural intervention with families to reduce relapse. Br. J. Psychiatry, 153: 532-42, 1988.

21. TARRIER, N.; BARROWCLOUGH, C.; VAUGHN, C.; BAMRAH, J. S.; PORCEDDU, K.; WATTS, S.; FREEMAN, H. Community management of schizophrenia. A two-year follow-up of a behavioural intervention with families. Br. J. Psychiatry, 154: 625-8, 1989.

22. THORNTON, N, J. F.; PLUMMER, E.; SEEMAN, M. V. LITTMANN, S. K. Schizophrenia: group support for relatives. Can. J. Psychiatry, 26: 341-4, 1981.
23. TUDOR, J. F. \& GOVE, W. R. The effect of sex role differences on the social control of mental illness. J. Health Soc. Behav., 18: 98-112, 1977.

24. VAUGHN, C. E. Patterns of emotional response in the families of schizophrenic patients. In: Goldstein, M. J.; Hand, I. ; Hahlweg, Treatment of schizophrenia. New York, Springer Verlag, 1986. p. 97-106.

25. VAUGHN, C. E. \& LEFF, J. P. The influence of family and social factors on the course of psychiatric illness: a comparison of schizophrenic and depressed neurotic patients. Br. J.Psychiatry, 129: 125-37, 1976.

26. VAUGHN, C. E.; SNYDER, K. S.; JONES, S.; FREEMAN, W. B.; FALLOON, I. Family factors in schizophrenic relapse: replication in California of British research on expressed emotion. Arch. Gen. Psychiatry, 41: 1169-77, 1984.

27. WATT, D. C.; KATZ, K. \& SHEPHERD, M. The natural history of schizophrenia: A 5-year follow-up of a representative sample of schizophrenics by means of a standardized clinical and social assessment. Psychol. Med., 13: 663-70, 1983.

28. WEISSMAN, M.M. The assessment of social adjustment. Arch. Gen. Psychiatry, 32:357-65, 1975.

29. WIG, N. N.; MENON, D. K.; BEDI, H.; GHOSH, A.; KUIPERS, L.; LEFF, J.; OKORTEN, A.; DAY, R.; SARTORIUS, N.; ERNBERG, G.; JABLENSKY, A. Expressed emotion and schizophrenia in North India. I: Cross-cultural transfer of ratings of relatives' expressed emotion. Br. J. Psychiatry, 151: 156-60, 1987.

30. WIG, N. N.; MENON, D. K.; BEDI, H.; LEFF, J.; KUIPERS, L. GHOSH, A.; DAY, R.; KORTEN, G.; ERNBERG, G.; SARTORIUS, N. JABLENSKY, A. Distribution of expressed emotion components among relatives of schizophrenic patients in Aarhus and Chandigarh. Br. J. Psychiatry, 151: 160-5, 1987. 